\title{
World Journal of
Pediatric Surgery lump in children - laparoscopic technique versus open surgery: a comparative study in low-middle income country perspective
}

\begin{abstract}
Mohammad Zonaid Chowdhury, Md Abdullah Al Farooq, M A Mushfiqur Rahman, Tanvir Kabir Chowdhury (D)
\end{abstract}

To cite: Chowdhury MZ, Farooq MAA, Rahman MAM, et al. Management of early appendicular lump in children laparoscopic technique versus open surgery: a comparative study in low-middle income country perspective. World Jnl Ped Surgery 2020;3:e000131. doi:10.1136/wjps-2020-00013

Received 30 March 2020 Revised 13 June 2020 Accepted 15 June 2020
Check for updates

Cㄱ Author(s) (or their employer(s)) 2020. Re-use permitted under CC BY-NC. No commercial re-use. See rights and permissions. Published by BMJ.

Department of Pediatric Surgery, Chittagong Medical College, Chattogram, Bangladesh

Correspondence to Dr Tanvir Kabir Chowdhury; ivan_tanvir@yahoo.com

\section{ABSTRACT}

Background In the pediatric population, appendectomy is one of the most common emergency operations. Laparoscopic appendectomy (LA) is an accepted way of dealing with suspected uncomplicated appendicitis in children. The role of laparoscopy in appendicular lump is more controversial and remains undefined and is not well practiced in low-middle income countries. The aim of this study was to determine a better surgical treatment plan for early appendicular lump in children.

Methods This prospective observational study was performed in Pediatric Surgery Department of Chittagong Medical College and Hospital for a period of 1 year from April 2018 to March 2019. Sixty children with appendicular lump selected consecutively as per eligibility criteria underwent either LA or open appendectomy $(0 \mathrm{~A})$, that is, 30 children per group. They were followed up until hospital discharge to observe outcomes.

Results There were no differences in terms of patient's age, sex, clinical presentation and laboratory findings between the two groups. Postoperative pain severity was significantly less in the LA group than that in the $0 \mathrm{~A}$ group $(p<0.01)$. The incidence of wound infection was significantly lower in the LA group than that in the $0 \mathrm{~A}$ group $(6.7 \%$ in $L A$ and $46.7 \%$ in $0 A ; p<0.01)$. Children in the LA group had a shorter duration of hospital stay in comparison to the OA group [median (IQR) was 8 (5.7511.25) days and 12 (7.75-18.00) days, respectively, in LA and $0 A$ groups; $p=0.01]$.

Conclusion The study findings suggest that $L A$ is feasible and should replace $O A$ in cases of early appendicular lump in children.

\section{INTRODUCTION}

The incidence of acute abdominal pain in children visiting pediatric and emergency departments is about 5\%, and among all acute causes appendicitis has an incidence of $12.7 \%$, representing the most common reason for abdominal surgery. ${ }^{1}$ The prevalence of appendicular lump in acute appendicitis is $2 \%-10 \%$ of cases. ${ }^{2}$ An appendicular

\section{Key messages}

What is already known about this subject?

- There is controversy about early appendectomy for appendicular lump.

- Laparoscopic appendectomy (LA) is being done in the developed world for appendicular lump.

- LA has less complications.

What are the new findings?

- Early appendectomy can be done in appendicular lump.

- LA is not widely practiced in the low-middle income countries, especially for appendicular lumps.

- Open appendectomy has more complications, more hospital stays and more postoperative pain.

LA has better results even in resource poor settings.

How might it impact on clinical practice in the foreseeable future?

- Low-middle income countries should increase thei volume of laparoscopic surgeries for early appendicular lump to achieve better patient outcomes.

- The findings of the study will encourage authorities to set up laparoscopic instruments even in resource poor settings.

lump is one of the outcomes of acute appendicitis usually from third day of inflammation, formed by inflamed appendix surrounded by greater omentum, bowel loops including edematous cecal wall and ileum, which can be felt as tender mass in right iliac fossa. The term appendicular lump has been used synonymously with appendix mass, appendicular mass, or appendiceal lump in the literature. ${ }^{3-5}$ Immediate appendectomy in children with appendicular lump is an alternative to conventional conservative treatment. In adults appendicular lump is well formed, but in children appendicular lump is not well formed owing to the underdeveloped greater 
omentum, which is unable to give much assistance in localizing the infection. Early recovery and complete cure during the first admission are the main advantages of immediate appendectomy for appendicular lump in children. The common complications after immediate appendectomy are wound infection, intestinal fistula, small bowel obstruction, intra-abdominal abscess, and sepsis. ${ }^{2}$ Nowadays, a minimally invasive laparoscopic technique is possible, safe, and effective and is gaining popularity among patients and surgeons. However, very few centers are performing laparoscopic surgeries for appendicular lump in most low-middle income countries. The present study was conducted to compare the outcomes of different procedures (laparoscopic vs open surgery) for treating early appendicular lump in children in a lowmiddle income country.

\section{METHODS}

This was a hospital-based, prospective, observational study carried out in the Department of Pediatric Surgery, Chittagong Medical College and Hospital from April 2018 to March 2019. All children aged 2-12 years who were admitted and diagnosed with appendicular lump in this department during this period were selected for the study. Children who underwent appendectomy with diagnosed case of appendicular lump either clinically or with ultrasonography, children with palpable appendicular lump under general anesthesia, and children with clinical diagnosis of acute appendicitis without lump formation but on surgical exploration appendicular lump was found were included in the study. Clinically, a lump was defined as a palpable mass in the right iliac fossa on superficial or deep palpation during bedside clinical examination or during abdominal palpation under anesthesia before making an incision. Since the lump might be missed clinically in the obese and in those with marked tenderness and rigidity at presentation, ultrasonogram (USG) and findings during surgery were also included. On USG an appendicular lump was considered present if the sonologist described the lesion as an appendix mass, lump, or abscess with or without visualizing the appendix inside the mass. During surgery periappendiceal adhesion of omentum or coils of small or large bowel, which needed to be separated from the appendix during an appendectomy, was considered as appendicular lump. All preoperative and sonological findings were further confirmed during surgery. If no per-operative mass was found, they were excluded from the study. An appendix was defined as perforated if visible perforation was present, phlegmonous if signs of inflammation and focal tissue edema existed with no loculated fluid collection to suggest the formation of an abscess, and gangrenous if signs of necrosis were evident without visible perforations. All surgeries were done during the first admission; patients who came for interval appendectomy were excluded from the study. Also, children who had lump in the right iliac fossa due to worm bolus, ileocecal tuberculosis, and carcinoid tumor mimicking acute appendicitis were excluded from the study. Eligible patients were allocated into one of the two groups: laparoscopic appendectomy (LA) (group A) and open appendectomy (OA) (group B), based on the type of surgery they underwent. The decision of performing open or laparoscopic surgery was not made by the authors; rather it depended on the individual surgeon's preferences, which were based on timing of surgery, availability of consultants during the after-hours, surgeons having the skill of performing laparoscopic surgery, availability of skilled anesthetist during the after-hours to deal with a patient undergoing laparoscopy, and parental desire. Thirty consecutive cases of $\mathrm{OA}$ and 30 consecutive cases of LA were followed and included for analysis in this study. Per-operative complications, operative time, postoperative pain, postoperative wound infection, and length of hospital stay were compared between the groups with t-test, Mann-Whitney $\mathrm{U}$ test, $\chi^{2}$ test or Fisher's exact test as appropriate using SPSS V.22. A $p$ value $<0.05$ was considered statistically significant.

\section{RESULTS}

There were a total of 60 patients distributed evenly in each group. Male to female ratio was 2.3:1, but there was no significant difference between groups with regard to sex and age (mean age $8.80 \pm 2.61$, range $4-12$ years in group A vs mean 9.83 \pm 2.41 , range $5-2$ years in group B; $\mathrm{p}=0.12$ ). Both the groups were comparable in terms of distribution of physical findings, the differential counts of white cell and preoperative USG findings.

Per-operative findings between two groups are described in table 1. Perforated and inflamed appendixes were common per-operative findings. The OA group had more perforated appendix and presence of pus; whereas the LA group had more phlegmonous appendix. However, the differences between the two groups were not statistically significant.

There was no statistically significant difference $(\mathrm{p}=0.63)$ regarding duration of operation between groups. Mean $( \pm \mathrm{SD})$ duration of operation was $80.5( \pm 39.4) \mathrm{min}$ and $80.67( \pm 27.63) \mathrm{min}$, respectively, in LA and OA groups

\begin{tabular}{|c|c|c|c|}
\hline \multirow[b]{2}{*}{$\begin{array}{l}\text { Per-operative } \\
\text { findings }\end{array}$} & \multicolumn{2}{|l|}{ Appendectomy } & \multirow[b]{2}{*}{$\begin{array}{l}\mathrm{P} \\
\text { value }\end{array}$} \\
\hline & $\begin{array}{l}\text { Laparoscopic } \\
(n=30)\end{array}$ & Open $(n=30)$ & \\
\hline \multicolumn{4}{|l|}{$\begin{array}{l}\text { Appendix } \\
\text { condition }\end{array}$} \\
\hline Perforated & $16(53.3 \%)$ & $21(70.0 \%)$ & 0.26 \\
\hline Phlegmonous & $13(43.3 \%)$ & 7 (23.3\%) & 0.17 \\
\hline Gangrenous & $1(3.3 \%)$ & $2(6.7 \%)$ & 1.00 \\
\hline Presence of pus & 17 (56.7\%) & $23(76.7 \%)$ & 0.61 \\
\hline
\end{tabular}

*Data were presented as frequency (percentage). $P$ values were derived from $\chi^{2}$ test. 
Table 2 Pain severity observation on fifth postoperative day among the patients

\begin{tabular}{llcl}
\hline \multirow{2}{*}{$\begin{array}{l}\text { Pain } \\
\text { severity }\end{array}$} & $\begin{array}{l}\text { Appendectomy } \\
\text { Laparoscopic } \\
(\mathbf{n}=30)\end{array}$ & $\begin{array}{l}\text { Open } \\
(\mathbf{n}=30)\end{array}$ & \multirow{2}{*}{ P value* $^{*}$} \\
\hline No & $12(40.0 \%)$ & $0(0 \%)$ & \\
Mild & $17(56.7 \%)$ & $23(76.7 \%)$ & $<0.01$ \\
Moderate & $1(3.3 \%)$ & $7(23.3 \%)$ & \\
\hline
\end{tabular}

${ }^{*}$ Data were presented as frequency (percentage). $\mathrm{P}$ values were derived from $\chi^{2}$ test.

with a range of 30-165 and 30-135 min. Median (IQR) of the duration of operation was $66(45-120) \mathrm{min}$ and 77.5 (60-105) min, respectively.

Postoperative pain was assessed by verbal rating scale and a visual analog scale (VAS). The patient rated the pain verbally (eg, none, mild, moderate, severe) and the patient indicated intensity of pain on a line typically $10 \mathrm{~cm}$ long marked from 'no pain' at one end to 'severe pain' at the other end. The pain was then scored in centimeters or millimeters, often with a sliding marker to aid measurement.

On the fifth postoperative day, most of the patients in LA group had either no or mild degree of pain as assessed by VAS. In contrast, in OA group most of the patients had either moderate or mild degree of pain. The degree of pain was significantly $(p<0.01)$ higher in OA group than that in LA group (table 2). Similar to the fifth postoperative day, on the 10th postoperative day pain severity was significantly greater in most of the patients in OA group compared with those in LA group (table 3).

The incidence of wound infection was significantly higher in OA group in comparison to LA group (table 4). Likewise, the incidence of wound dehiscence was significantly higher in OA group compared with LA group. It is to be noted that none of the LA cases had wound dehiscence. In OA group there was one case of ileal perforation with dehiscence wound and another case of fecal fistula.

Mean $( \pm \mathrm{SD})$ duration of hospital stay was $9.00( \pm 4.87)$ days and $14.77( \pm 9.35)$ days, respectively, in LA and OA groups with a range of 4-30 and 4-38 days. Median (IQR) duration of hospital stay was $8(5.75-11.25)$ days and

Table 3 Pain severity observation on the 10th postoperative day among the patients

\begin{tabular}{llcl}
\hline & \multicolumn{2}{l}{ Appendectomy } & \\
\cline { 2 - 3 } Pain severity & $\begin{array}{l}\text { Laparoscopic } \\
(\mathbf{n}=30)\end{array}$ & $\begin{array}{l}\text { Open } \\
(\mathbf{n}=30)\end{array}$ & \multirow{2}{*}{ P value* $^{*}$} \\
\hline No & $15(50.0 \%)$ & $0(0 \%)$ & \\
Mild & $14(46.7 \%)$ & $16(53.3 \%)$ & $<0.01$ \\
\hline Moderate & $1(3.3 \%)$ & $14(46.7 \%)$ & \\
\hline
\end{tabular}

*Data were presented as frequency (percentage). $P$ values were derived from $\chi^{2}$ test.
Table 4 Comparison of postoperative wound condition between two groups

\begin{tabular}{|c|c|c|c|}
\hline \multirow[b]{2}{*}{$\begin{array}{l}\text { Wound } \\
\text { condition }\end{array}$} & \multicolumn{2}{|l|}{ Appendectomy } & \multirow[b]{2}{*}{$P$ value* } \\
\hline & $\begin{array}{l}\text { Laparoscopic } \\
(n=30)\end{array}$ & $\begin{array}{l}\text { Open } \\
(n=30)\end{array}$ & \\
\hline \multicolumn{4}{|c|}{ Wound infection } \\
\hline No & 28 (93.3\%) & $16(53.3 \%)$ & $<0.01$ \\
\hline Yes & $2(6.7 \%)$ & $14(46.7 \%)$ & \\
\hline \multicolumn{4}{|c|}{$\begin{array}{l}\text { Wound } \\
\text { dehiscence }\end{array}$} \\
\hline No & $30(100 \%)$ & $22(73.4 \%)$ & $<0.01$ \\
\hline Yes & $0(0 \%)$ & $8(26.6 \%)$ & \\
\hline
\end{tabular}

${ }^{*}$ Data were presented as frequency (percentage). $P$ values were derived from $\chi^{2}$ test.

12 (7.75-18.00) days, respectively. Patients who underwent OA had a significantly $(\mathrm{p}=0.01)$ longer duration of hospital stay compared with those who underwent LA.

A logistic regression analysis showed that only presence of pus after exploration and type of surgery significantly predicted development of complications. Since the OA group had more complications, a comparative analysis was done between patients with complications versus those without complications in OA group. It was found that only presence of pus ( 11 vs 3 respectively, $\mathrm{p}=0.00$ ) was significantly different between these subgroups and that there was no significant difference with regard to clinical features, examination and investigation findings and duration of surgery.

\section{DISCUSSION}

The indications for LA have rapidly expanded from simple to complicated acute appendicitis and more recently to appendicular lump. ${ }^{34}$ OA can be performed during the index admission in most patients with an appendicular lump in children. Although OA has been associated with a considerable risk of complications, the majority of them are attributed to intestinal injury, wound infection, intra-abdominal abscess, enteric fistula, and respiratory complications. ${ }^{35-7}$

In this study, among the children who underwent $\mathrm{OA}$, three cases had minor wound infections, and there were nine major complications. One was a small bowel perforation with fecal fistula requiring stay in hospital for almost 35 days, and another was adhesions with ileal perforation with wound dehiscence. The other seven $(23.3 \%)$ complications were major wound dehiscence needing resuturing and stay in hospital for 11-38 days. Similar observations also were reported by Padankatti et $a l^{8}$ It is reasonable therefore to anticipate a favorable role for the laparoscopic approach in the management of the appendicular lump, given that LA has been associated with a significant reduction in wound infection rate when compared with OA. ${ }^{39}$ In the current study, only two patients $(6.7 \%)$ who underwent LA for appendicular 
lump developed wound infection, in comparison to 14 patients $(46.7 \%)$ in OA group. This lower infection rate might be related to removal of the perforated appendix through the trocar or to an endoscopic bag, avoiding direct contact with the wounds, and the infected intraabdominal fluid was also aspirated thoroughly during the laparoscopic approach. Avoiding the laparoscopic approach in complicated appendicitis in children has previously been suggested because of the increased risk of postoperative intra-abdominal abscesses ${ }^{810}$; however, none of our patients developed such complications. Several factors might have contributed to this result. All of our procedures were performed by experienced laparoscopic pediatric surgeons, and a good peritoneal wash with a large amount of normal saline was a routine procedure in all cases, in addition to very strict intravenous and oral antibiotic regimens. On the other hand, the OA group had a $46.7 \%$ wound infection rate, which was higher than many reported studies. This high wound infection rate is not uncommon in cases with perforated appendix or appendicular abscess. Complication rates for appendix mass have been reported to be ranging from $15 \%$ to $50 \% .{ }^{511} 12$ There are several possible reasons for this higher rate, including (1) most OAs were done by junior trainees during the after-hours under spinal anesthesia, (2) lack of proper autoclaving, (3) inadequate peritoneal lavage, and (4) relatively more patients with appendicular perforation and abscess. Although infection rate was high, only eight patients needed secondary closure of the wound.

There are several advantages to the laparoscopic approach in complicated appendicitis. It enables visualization of the whole abdominal cavity and a thorough peritoneal lavage, which is difficult with a small incision. In open surgery, atypical localization of the appendix or inaccurate diagnosis may require an extension of the incision as well. The laparoscopic approach also allows patients to become mobile and pain free much faster, due to less trauma to the muscles and fascia. ${ }^{13}$ The benefit of a less severe postoperative pain in LA was also observed in this study. Similarly, Padankatti et al observed that children who underwent LA for appendicular mass had less pain after surgery, more so in the early postoperative period, and a reduced requirement for parenteral analgesia. $^{8}$ Oral non-steroidal anti-inflammatory drugs were sufficient in those patients.

In this study, only five $(16.6 \%)$ cases required conversion to open surgery for severe adhesions, and one of them subsequently required secondary closure for wound infection. Agrawal et al showed that only one case $(1.92 \%)$ required conversion to open procedure due to failure of identification of appendicular base of a sloughed-out appendix. ${ }^{14}$ Hospital stay was significantly higher in OA group than LA group $(\mathrm{p}=0.01)$. Ramachandran et al observed that the average postoperative hospital stay was 5 days in LA group and 7.5 days in OA group. In our hospital it was higher because most of the patients came from rural areas and we wanted to keep the patients under our direct supervision for an extended period.

Our study has several limitations. The patients were not randomly selected, and there was a possibility that more severe cases were operated by OA. Logistic regression analysis showed that type of surgery and presence of pus were significant predictors of complications. The OA group had relatively more cases of perforated appendix and patients with presence of pus. However, this difference was not statistically significant. Moreover, there was no significant difference with regard to clinical features, examination, and investigation finding between patients of OA group with complications versus those without complications, which slightly ruled out selection bias. Nonetheless, these might have a negative influence on pain severity and complication rates. This was also a single-center study; sample size was small, and follow-up period was relatively short; hence the results should not be generalized.

In conclusion, LA can be carried out as a simple procedure in the presence of appendicular lump in children. This procedure offers less severe postoperative pain, fewer wound infection, and earlier discharge from hospital compared with OA.

Contributors CMZ contributed to manuscript preparation and data collection. CTK contributed to manuscript preparation. RMAM and FAA contributed to manuscript editing and review.

Funding The authors have not declared a specific grant for this research from any funding agency in the public, commercial or not-for-profit sectors.

Competing interests This study was part of a thesis work of the principal author for Masters of Surgery under University of Chittagong.

Patient consent for publication Parental/guardian consent obtained.

Ethics approval The study was approved by the Ethical Review Committee of Chittagong Medical College.

Provenance and peer review Not commissioned; externally peer reviewed.

Data availability statement Data are available upon reasonable request. All data relevant to the study are included in the article. Further data will be available upon request in the following ORCHID ID: https://orcid.org/0000-0002-1661-2111

Open access This is an open access article distributed in accordance with the Creative Commons Attribution Non Commercial (CC BY-NC 4.0) license, which permits others to distribute, remix, adapt, build upon this work non-commercially, and license their derivative works on different terms, provided the original work is properly cited, appropriate credit is given, any changes made indicated, and the use is non-commercial. See: http://creativecommons.org/licenses/by-nc/4.0/.

\section{ORCID iD}

Tanvir Kabir Chowdhury http://orcid.org/0000-0002-1661-2111

\section{REFERENCES}

1 Caruso AM, Pane A, Garau R, et al. Acute appendicitis in children: not only surgical treatment. $J$ Pediatr Surg 2017;52:444-8.

2 Kaya B, Sana B, Eriș C, et al. Aapendiküler kitlelerde erken apendektomi. Ulus Travma ve Acil Cerrahi Derg 2012;18:71-4.

3 Chowdhary SK, Talukdar R, Singh NK. Assessment of the relevance of interval appendicectomy in treatment of appendicular lump: a prospective study. Int J Sci Study 2016;4:162-6.

4 Ram KR, Chandana S, Koshti S. A study of outcome of nonoperative versus operative management in 50 cases of appendicular lump. Int Surg J 2017;4:2233-7.

5 Kumar CD, Abhijit S, Arupjyoti B, et al. Laparoscopic appendicectomy in appendicular lump. International Journal of Pharmaceutical Science Invention 2013;2:1-2. 
6 Senapathi PSP, Bhattacharya D, Ammori BJ. Early laparoscopic appendectomy for appendicular mass. Surg Endosc 2002;16:1783-5.

7 Goh BKP, Chui CH, Yap TL, et al. Is early laparoscopic appendectomy feasible in children with acute appendicitis presenting with an appendiceal mass? A prospective study. $J$ Pediatr Surg 2005;40:1134-7.

8 Padankatti LR, Pramod RK, Gupta A, et al. Laparoscopic versus open appendicectomy for complicated appendicitis: a prospective study. J Indian Assoc Pediatr Surg 2008;13:104-6.

9 Ali R, Anwar M, Akhtar J. Laparoscopic versus open appendectomy in children: a randomized controlled trial from a developing country. J Pediatr Surg 2018;53:247-9.

10 Meshikhes AW. Management of appendiceal mass: controversia issues revisited. J Gastrointest Surg 2008;12:767-75.
11 Henry MCW, Gollin G, Islam S, et al. Matched analysis of nonoperative management vs immediate appendectomy for perforated appendicitis. J Pediatr Surg 2007;42:19-24.

12 Fugazzola P, Coccolini F, Tomasoni M, et al. Early appendectomy vs. conservative management in complicated acute appendicitis in children: a meta-analysis. J Pediatr Surg 2019;54:2234-41.

13 Meguerditchian AN, Prasil P, Cloutier R, et al. Laparoscopic appendectomy in children: a favorable alternative in simple and complicated appendicitis. J Pediatr Surg 2002;37:695-8.

14 Agrawal V, Acharya H, Chanchlani R, et al. Early laparoscopic management of appendicular mass in children: still a taboo, or time for a change in surgical philosophy?. J Minim Access Surg 2016;12:98-101. 